\title{
Modifications of Long Economic Cycles and Prospects for Global Economic Dynamics in 2021-2050
}

\author{
V. G. Klinov ${ }^{a}$ * and A. A. Sidorov ${ }^{a}$ \\ ${ }^{a}$ Moscow State Institute of International Relations, Ministry of Foreign Affairs of the Russian Federation, \\ Moscow, 119454 Russia \\ *e-mail:vg.klinov@mail.ru
}

Received October 19, 2020; revised October 23, 2020; accepted November 16, 2020

\begin{abstract}
The article presents an analysis of the nature and causes of changes observed in the long economic cycles (Kondratieff waves) of global economic development of the first half of the 21st century. The forms of these modifications and the time boundaries of the current long economic cycle are defined. A reduction of the ascending wave of the long economic cycle to 15 years and an expected reduction of the descending wave to 15 years are noted. The reasons for the reduced durations of long economic cycle phases are associated with the proliferation of microelectronic information and communication technology and with the aggravation of global competition by major developing economies. Prospects for global economic dynamics in the next 30 years and possible time boundaries of the next long economic cycle are delineated.
\end{abstract}

Keywords: long economic cycles, Kondratieff waves, ascending wave, descending wave, business situation, global economy, advanced economies, developing economies, modifications of long economic cycles, longterm forecasting

DOI: $10.1134 / \mathrm{S} 1075700721030060$

Global economic dynamics during the fourth long economic cycle of 1950-1995. The typical patterns of long economic economic cycles are most clearly illustrated by global economic dynamics of the second half of the 20th century. The ascending wave (1950-1973) and descending wave (1974-1995) of that cycle were of approximately equal duration. The ascending wave was characterized by higher indicators of the average annual growth rate (AAGR) of GDP per capita and of labor productivity.

A prominent researcher of cyclical processes of the global economy Solomos Solomou (Cambridge University, UK) believed that neither Kondratieff waves nor Kuznets swings are regularly recurring features of modern economy. However, he did note that the pattern of post-war economic growth appears to fall within the range expected from the Kondratieff wave framework [1].

The formation of the long economic cycle of the second half of the 20th century was majorly influenced by the most powerful economy in the world and S\&T leader, the United States, as well as the other major advanced economies (AE) in the aggregate, the Group of Seven (G7), which along with the United States includes Japan, Germany, the United Kingdom, France, Italy, and Canada.

The GDP per capita dynamics of the S\&T leader characterizes global scientific and technological achievements more accurately than AAGRs of GDPs per capita of the $\mathrm{G} 7$ countries. The latter value reflects not only the dynamics of the S\&T progress on the global scale, but also the speed with which other large AEs catch up with the S\&T leader or lag behind it.

Similarity in long economic cycles of S\&T leaders facilitates the study of patterns and the theory of long economic waves of economic development, while disruptions in the synchrony of major economies' cycles complicate such research. However, in view of the diversity of economic development levels of many national economies, especially among developing economies (DE), such disruptions are inevitable.

The GDP per capita dynamics of the G7 countries differs from those of the S\&T leader due to the catchup growth of the other AEs. Thus, in 1950-1973, the AAGR of the GDP per capita of the G7 countries reached $3.9 \%$, exceeding the corresponding value for the United States by $1.2 \mathrm{pp}$.

DEs started their catch-up growth later. Due to their lagging behind, the AAGR of the global GDP per capita in 1950-1973 reached $2.9 \%$, i.e., exceeded the leader's indicator by $0.2 \mathrm{pp}$, which is six times less than the difference between the leader and G7.

Another classic feature present in the Kondratieff wave of the second half of the 20th century is the fact that the ascending wave was interrupted by only one significant global slowdown in business activity. The AAGR of the global real GDP per capita approached 
zero at its lowest point in 1957-1958, but did not reach negative values.

The descending wave (1974-1995) included three global cyclical recessions, one in each decade of this wave (in 1975, 1982, and 1991). In these years, the AAGR of the global real GDP per capita reached negative values, i.e., the absolute value of the global real GDP per capita decreased during recessions.

To sum up, classic long economic cycle patterns present in the second half of the 20th century include: approximately equal duration of the ascending wave and descending wave; higher AAGR of GDP per capita and higher labor productivity in the ascending wave compared to the descending wave; a smaller number and depth of global medium-term recessions in the ascending wave compared to the descending wave.

Modifications of the ascending wave of the beginning of the 21 st century. In the 21 st century the classic long economic cycle patterns were somewhat modified. The questions of the specific forms and causes of this modification and of the time boundaries of the current fifth long economic cycle remain, at present, open. An attempt to fill this gap is made below.

Analysis of the labor productivity index in the business sector of the US economy demonstrates that the 1996-2010 period generally had the signs of the ascending wave of the fifth long economic cycle. The 2011-2019 period was characterized by significantly lower labor productivity dynamics, which precludes it from being considered part of the ascending wave. The AAGR in 1996-2010 reached $2.7 \%$ compared to $1.4 \%$ in 1974-1995 and 2.8\% in 1950-1973. After 2010, the AAGR declined sharply and in 2011-2019 amounted to $0.9 \%^{1}$.

Thus, based on the labor productivity indicator of the S\&T leader, a reduction of the ascending wave duration to 15 years compared to $24(1950-1973)$ in the previous 1950-1995 long economic cycle can be distinguished as a modification of the current long economic cycle.

The deepest global recession since the Great Depression of 1929-1932 was observed in 2009 [3, p. 10]. That signaled the imminent end of the first ascending wave of the 21st century, much as the Great Depression crisis ended the first ascending wave of the 20th century (1896-1929).

A similar position regarding the role and depth of the 2008-2009 crisis is taken in [4]. The authors note that the 2008-2009 crisis "was a crisis between the upward and downward phases of the fifth Kondratieff wave" and that "such turning-point crises gain especial force" [4, p. 131].

There is other evidence that supports the hypothesis that the second decade of the 21st century marked the beginning of an entirely new period of global economic development, and possibly of globalization as

\footnotetext{
${ }^{1}$ Calculated from [2].
}

well, which seems to correspond to the descending wave of the long economic cycle. This refers to the decline in the elasticity of world trade to global GDP.

Globalization is generally characterized by faster growth of global trade compared to production. This was the case in 1996-2010: according to the WTO, the AAGR of global exports at constant prices amounted to $5.1 \%$, of global GDP, to $2.9 \%$. The former indicator exceeded the latter by $2.2 \mathrm{pp}$, or 1.8 times.

The calculations for 1992-2010, disregarding strict boundaries of the ascending wave of the fifth long economic cycle (turning points in dynamics of different indicators generally do not coincide), are even more revealing, as 1991 was the beginning of a period of increasing global GDP elasticity of global trade growth. According to the WTO, the AAGR of global exports at constant prices during this period amounted to $5.4 \%$, of global GDP, to $2.8 \%$. The former indicator exceeded the latter by $2.6 \mathrm{pp}$, or almost two times.

The second decade of the 21 st century presents a different picture. In 2011-2019 the AAGR of global exports as well as global GDP at constant prices amounted to $2.7 \%$, i.e., the dynamics of the two indicators did not differ, and in some years trade even grew slower than production. The last year relatively prosperous in this respect was 2011. Calculations for 20122019 based on WTO data show that the AAGR of global exports at constant prices amounted to $2.4 \%$, of global GDP, to $2.7 \%^{2}$, i.e., the difference between the two indicators became negative.

The decline in global GDP elasticity of global trade growth seems to have taken on a long-term nature and started before the political upheavals associated with economic sanctions and retaliatory measures and before the protectionist policies of US President Donald Trump. This decline signifies the beginning of a period of relatively less-favorable economic conditions.

The ascending wave of the beginning of the 21st century was peculiar in that out of the G7, major AEAEs, only three countries (the United States, Great Britain, and Canada) followed the classic pattern of development and had higher economic growth rates in the ascending wave compared to the preceding descending wave. The other four G7 countries turned out to be more poorly prepared for global competition with DEs, which weakened the ascending wave and accelerated the onset of the descending wave in these countries. The weakening of the ascending wave was also reflected in the increased number of sharp decelerations of the pace of economic development on the global scale in 1998, 2001, and 2012.

Another feature of the ascending wave of the fifth long economic cycle was accelerated growth of the major DEs, China, which has become more attractive for investment in production and sales of new types of high-tech products than most major AEs.

\footnotetext{
${ }^{2}$ Calculated from [5].
}

Vol. 32 No. $3 \quad 2021$ 
Table 1. Average annual growth rates of GDP per person employed, PPP, constant 2017 international \$ (labor productivity)

\begin{tabular}{l|c|c}
\hline \multicolumn{1}{c|}{ Country } & $1996-2010$ & $2011-2019$ \\
\hline High-income economies & 1.5 & 0.9 \\
USA & 1.9 & 0.9 \\
Japan & 0.9 & 0.4 \\
Germany & 0.8 & 0.8 \\
UK & 1.3 & 0.5 \\
France & 0.8 & 1.0 \\
Italy & 0.2 & -0.4 \\
Canada & 1.5 & 0.8 \\
Low \& middle income economies & 3.8 & 3.8 \\
China & 9.2 & 7.3 \\
India & 4.7 & 5.7 \\
\hline
\end{tabular}

Source: [7].

According to the research firm PricewaterhouseCoopers (PwC), in 2015 the combined GDP of the seven major DEs-China, India, Indonesia, Brazil, Russia, Mexico, and Turkey (E7)-equaled the GDP at purchasing power parity (PPP) of the G7, while in 1995 it was two times smaller than the GDP of the G7. In 2016, China was ahead of the United States in terms of physical GDP. At PPP, China's GDP reached $18 \%$ of global GDP, while the US GDP is at $16 \%$ [6, p. 4].

According to Table 1, in AEs in general and specifically in most $\mathrm{G} 7$ countries with the exception of Germany and France, the ascending wave of 1996-2010 was characterized by higher indicators of GDP at PPP per person employed (labor productivity).

In DEs (excluding China) AAGRs of GDPs per person employed were higher in the descending wave (2011-2019). In India (the second largest economy among DEs after China) this indicator was higher in the descending wave compared to the ascending wave by $1 \mathrm{pp}$.

In China the AAGR of the GDP per person employed was higher in the ascending wave than in the descending one by $1.9 \mathrm{pp}$. It is noteworthy that in the first long economic cycle of the 21st century China already "kept pace" with AEs in this regard and, most importantly, with the United States.

According to the World Bank, the AAGR of the global real GDP per capita (at the exchange rate) in 1996-2010 was $1.7 \%$, the same value as in 2011-2019. Also according to the World Bank, at PPP this indicator was $2.3 \%$ in $1996-2010$ and $2.2 \%$ in 2011-2019 [7].

The descending wave of the second half of the 20th century already showed signs of impending modifications of the long economic cycle, which manifested to a great extent in the first ascending wave of the 21st century.

A significant feature of the business situation in the United States in the second half of the 1960s was that by this time the most intense stage of the ascending wave was over and the slowing-down stage had begun. The decline in the return on investment in the United States in 1968-1973 made the major AEs of Western Europe and Japan more attractive to investors than the United States. During the descending wave these countries had the opportunity for catch-up growth in the medium term, which enabled them to reduce the gap between them and the United States in terms of GDP per capita.

However, in the long economic run they set themselves up for a future lag behind the United States. The United States focused on developing information and communication technology (ICT) in a new, microelectronic direction, facilitated acceleration of research and development (R\&D), intensification of scientific and technical information exchange, and development of cooperation in the field of $R \& D$ and production on a global scale. That created the conditions for a modification of the Kondratieff wave in the form of reduced duration of its phases, including the descending wave, during which focus was placed on developing new directions and new generations of technology.

As for the ascending wave of the fifth (current) long economic cycle, the reduction in its duration stems from the fact that ICT development in this period was focused on rationalizing, or process innovations (which constitute technological branch of S\&T progress) more than on expansionary, or product innovations (which constitute design branch of S\&T progress). The technological branch of S\&T progress is aimed at reducing the consumption of resources per unit of production by improving the production process by such means as automating the process or using new materials. The design branch of S\&T progress deals with creation of new types of end products. Design activities require significant increases in rates of investment in fixed assets for implementation of the developments and a long economic time for the creation of new industries or types of products (goods and services).

The predominance of the design branch of S\&T progress in the ascending wave of the second half of the 20th century ensured the relatively long economic duration of this phase. The duration of the ascending wave of the fifth (current) long economic cycle has decreased due to the shift of priorities towards the technological branch, which is a result of the general focus of the new microelectronic direction of ICT development on S\&T and labor substitution. In AEs, the weakening and shortening of the ascending wave was also exacerbated by the increased global competition with major DEs.

Factors of the development of DEs within the long economic cycle. The emerging modifications of the long economic cycle may be of paramount importance for long-term forecasting of global economic development. They are also important for assessing the timing 
of the change of phases of the current (fifth) long economic cycle and the beginning of the next (sixth) cycle.

It is important to determine how the possible synchronization of the dynamics of the largest economies in the world-China, the United States, and Indiawill affect long-term trends of global economic development during the future sixth long economic cycle.

The coincidence of the ascending wave (19962010) and descending wave (since 2011) in the United States and China creates the possibility of the dynamics of these two, possibly three (with India) countries synchronizing in the future ascending wave (estimated 2026-2040) and descending wave (2041-2055). The experience of the current long economic cycle of the 21 st century shows that a second ascending wave in the United States would create conditions for upswings in China and India.

Future directions of economic policies of major countries should also be considered. The dramatic changes in global economic conditions observed during the first two decades of the 21st century, the acceleration of economic growth in 2002-2007, the severe recession in 2008-2009, the rapid recovery in 2010 , and the slowdown of growth since 2011, were strongly influenced by economic policies of the largest and most powerful AEs and DEs.

The acceleration of economic growth in AEs after the global deterioration of the economic environment in 2001 was largely facilitated by the incentivization of housing construction in these countries through targeted policies of offering preferential mortgage loans to those who want to build houses. The United States stopped requiring mortgage applicants to provide information about their income and property values during this time. The accelerated economic growth in AEs had a positive impact on GDP dynamics of major DEs through growth of their exports to AEs, primarily to the United States. China's GDP almost doubled in 2002-2007.

This experiment ended after the cyclical recession of 2008-2009, when a financial crisis hit the United States and spread to the rest of the G7 countries. The financial crisis deepened the recession. In 2009, the GDP of AEs and the global GDP declined. The effect on DEs was generally limited to a sharp slowdown of economic growth caused by reduction of global exports replacing their rapid growth.

The rapid recovery from the recession in 2010 relied on fiscal and monetary measures of stimulating economic growth mainly financed by major DEs (especially China), which had strengthened their financial positions during the favorable global economic environment of 2002-2007. The Group of Twenty's (G20) assistance in coordinating efforts and the support of AEs enabled the major DEs to restore the pre-crisis values of global GDP per capita in an extremely short time (in 2010). The accumulated resources were largely spent on overcoming the reces- sion, i.e., opportunities for stimulating growth have been sharply reduced after $2011^{3}$.

The experience of the dynamics of the long economic cycle of the first two decades of the 21st century has shown that the domestic market is not enough for the complete success of major DEs. A significant component of their development is exports of new products to AEs, primarily to the United States.

Prospects for the completion of the descending wave of the first long economic cycle of the 21st century. Assuming, to a first approximation, the duration of the descending wave of the current long economic cycle as approximately equal to the ascending wave (19962010), the descending wave can be expected to end in the middle of 2021-2030. It is also possible that it will end in the second half of that decade, if overcoming the negative economic consequences of the coronavirus pandemic takes much longer than many experts currently assume.

Our estimate of the end date of the descending wave of the fifth long economic cycle almost completely coincides with the conclusion of [8], the authors of which note: "We are still in the downward phase of the fifth Kondratieff wave, which should end with the transition to the sixth cycle (its ascending wave) in the mid- or late 2020s" [8, p. 221].

Despite the noted possible exception, considering the 15-year duration of the ascending wave of 19952010 , let us name the dates of the descending wave of the fifth long economic cycle as, to a first approximation, 2011-2025.

A similar estimate of the end of the descending wave was given in abovementioned [4], where the authors note that the end of the "downward phase of the fifth Kondratieff long wave" and the beginning of the "upward phase of the sixth long wave" should be expected "around the 2020s, most likely in their middle, but possibly earlier" [4, p. 133].

Correspondingly, we estimate the dates of the ascending wave of the sixth long economic cycle as 2026-2040, the descending wave as 2041-2055. It seems likely that the S\&T leaders at the forefront of the next ascending wave will be China, the United States, and India.

Before the pandemic, the World Bank experts forecasted the AAGR of the GDP of DEs in 2019-2027 at an estimated $4.3 \%$, which is $1.6 \mathrm{pp}$ lower than in 2002-2007 [3, p. 27]. They allowed for the possibility of a sharp slowdown in global GDP dynamics during the forecasted decade due to a combination of unfavorable circumstances, particularly related to the United States' attempts to damage its main competitors. According to their calculations, a reduction of the AAGRs of the GDPs of the United States, China, and

\footnotetext{
${ }^{3}$ Statistical indicators that characterize financial conditions of major countries and directions of their economic policies in the first two decades are presented in [3, pp. 11, 13-16, 18, 21, 27, $30,31,37,39]$.
} 
the European Union (which together accounted for $50 \%$ of global GDP) by $1 \mathrm{pp}$ in 1 year can lead to a decrease in the AAGR of the global GDP by $1.7 \mathrm{pp}$, and of the GDP of DEs (excluding China) by $1.4 \mathrm{pp}$ [3, p. 27].

Actually, the coronavirus pandemic and measures taken to limit its spread caused a decline in 2020. According to the World Bank, the share of countries that will experience a decline in GDP per capita is about to reach its maximum value since 1870 [9, p. 3].

According to the IMF forecast of June 2020, the AAGR of the global real GDP will in 2020 be $-4.9 \%$, the corresponding indicator of AEs will decrease to $8.0 \%$, of DEs to $-3.0 \%$ [10, p. 7]. According to the World Bank estimates of the same date, the global real GDP will in 2020 decrease by $5.2 \%$, with the GDP of AEs decreasing by $7 \%$, of DEs, by $2.5 \%[9$, p. 4].

The scale of the possible decline of global GDP and the number of major countries affected by the 2020 decline makes negative consequences for the AAGR of GDP in 2021-2025 unavoidable. In this regard, it can be assumed that the indicators of the descending wave dynamics observed before 2020 will not improve in 2021-2025, but decline further.

The negative impact of the coronavirus pandemic on the dynamics of AEs appears to be stronger than its effect on DEs. This follows from the above estimates given by the IMF and the World Bank. At the same time, it is within reason to expect intensified creation of new generations of advanced technology in the United States and the end of the descending wave not in 2027, but in 2025. The scientific and technical basis of the following ascending wave can be creation and development of new generations of technology in the context of further digitalization of the economy. Digitalization is expected to be especially focused on improving the scientific and technical basis of the education and health systems. The authors of [11, p. 196] suppose that the new ascending wave will be based on nanotechnology and solar and nuclear energy.

According to the forecast for 2021-2030 by the research firm PwC, the AAGR of global GDP will amount to $2.9 \%$ [6, p. 10], which corresponds to an annual growth rate of GDP per capita of $2.1 \%$ (taking the averaged UN forecast of world population growth in the basic and minimum scenarios for this period at $0.8 \%)^{4}$.

In the present context the estimate of the AAGR of GDP per capita from the $\mathrm{PwC}$ forecast appears to be overstated. Firstly, the $\mathrm{PwC}$ forecast for objective reasons could not account for the negative consequences of the spread of the new coronavirus infection. Secondly, the forecast covers the second half of the 2020s, when the descending wave may be replaced by the following ascending wave (another reason why the AAGR of the GDP estimate should be lower for 2021-

\footnotetext{
${ }^{4}$ Calculated from [12].
}

2025 than for 2021-2030). We tried to account for both factors that PwC could not.

Our estimates are based on the probability of the descending wave indicators observed before 2020 declining in the upcoming period until its expected completion in 2025. Taking into account the World Bank and IMF estimates of the scale of the consequences of the 2020 coronavirus pandemic, which may still increase, and the sharp decline in the global GDP in 2020, we believe that the average annual growth rate of this indicator per capita (at PPP) for 2011-2025 may decrease to 1.7\%. Accordingly, our estimate of the AAGR of GDP per capita for the $1996-2025$ cycle as a whole is approximately $2 \%((2.3$ $+1.7) / 2)$ ).

Prospects for the development of economic conditions in the sixth long economic cycle (the second long wave of the 21st century). Centers that study long-term trends in global economic dynamics, such as $\mathrm{PwC}$, the World Bank, and the IMF, consider many important macroeconomic factors that affect global GDP dynamics in the long term. These factors include population and labor productivity growth, the impact of S\&T progress on productivity and on population growth, and dynamics of international trade and international investment flows (which propel an increasing number of countries into adopting advanced scientific and technological developments and accelerating economic development).

It should be noted that the research firm $\mathrm{PwC}$ constructs its forecasts on the basis of the following concept. The higher the GDP per capita of a country and the closer to the limit that can potentially be achieved with the use of the most advanced technology available globally (i.e., to a first approximation, to the GDP per capita of the United States) is, the fewer opportunities to increase the AAGR of GDP per capita by modernizing the economy by introducing advanced technology does that country have [6, p. 13]. This concept largely explains the current situation of average annual growth rates of GDPs per capita of major DEs being higher than those of major AEs. According to the PwC forecast, in 2017-2050 the AAGR of GDP will amount to $1.6 \%$ for the G7, to $3.5 \%$ for the E7, and to $2.6 \%$ for the world [6, p. 16]. Taking into account the forecasted AAGR of the population (according to the averaged UN estimates of the relevant basic and minimal scenarios for the G7 $(0.06 \%)$, the E7 $(0.21 \%)$, and the world $(0.66 \%)$ [12]), we obtain a rough estimate of the AAGR of global GDP per capita of $1.9 \%$.

Following the concept of advanced development of DEs, PwC predicts that in 2050 the top seven economically strongest (as measured by PPP) countries will include only one country from the current "Group of Seven" of AEs, namely the United States, which will be in third place, and six countries of the current E7, i.e., all except Turkey. 
As the economic power of the major DEs (China and India) had moved to leading positions, $\mathrm{PwC}$ predicted that the AAGR of global GDP will decrease in every following decade and amount to $2.7 \%$ in $2021-$ 2030 , to $2.5 \%$ in $2031-2040$, and to $2.4 \%$ in $2041-$ 2050 [6, p. 9]. In per capita terms that corresponds to $1.9 \%$ in $2021-2030,1.9 \%$ in $2031-2040$, and $2.0 \%$ in 2041-2050 [6, p. 16]. The AAGRs of world population in the corresponding decades are calculated on the basis of the averaged UN forecast of the basic and minimum scenarios and amount to $0.8,0.6$, and $0.4 \%$, respectively ${ }^{5}$.

The average AAGR of GDP per capita for the second cycle of the current century (2026-2055) as a whole will be, according to our calculations, approximately 1.9-2.0\% (based on the PwC forecast of global GDP dynamics and the forecast of global population dynamics in accordance with the average values of the population indicators in the basic and minimum UN scenarios).

Our calculations of global GDP dynamics for the estimated period of the second long economic cycle of the 21st century (2026-2055) are largely based on the 2017 long-term forecast by PwC. It should be mentioned that the experts considered their predictions optimistic. The forecast was based on the assumption that the globally predominating economic policy will be one favorable to ensuring high rates of economic development. Possible deviations from this rule, such as Donald Trump's protectionist policy, were not expected to be long-term. Such unexpected negative factors as a pandemic that would adversely affect the dynamics of the first Kondratieff wave of the 21st century were also not considered.

The most conservative estimates of the indicators of the sixth long economic cycle are no worse than the indicators of the current fifth cycle. To a first approximation, this means that the AAGR of global real GDP at PPP per capita will be $2.3 \%$ in 2026-2040, $1.7 \%$ in $2041-2055$, and $2.0 \%$ for the $2026-2055$ cycle on average.

Conclusions. The last descending wave has clearly shown that attempts of major AEs to weaken competition from major DEs by means of protectionist policies may result in general deterioration of global business situation, which affects AEs more severely than DEs [6, p. 4].

The conclusion for the United States and other AEs is obvious. The time of their dominance in the global market is ending. The right strategy is not to rely on protectionism, but to respond to the requirements of global competition, which becomes more acute as economic power of DEs increases, by restructuring the economy in favor of industries that can maintain or strengthen competitive advantage in the global market in the future.

\footnotetext{
${ }^{5}$ Calculated from [12].
}

The second long economic cycle of the 21st century will have high AAGR of global GDP per capita as a consequence of predominance of the economic power of DEs in the global economy and the fact that although the gap between major DEs and the United States in the level of GDP per capita will decrease, it will still remain significant.

As DEs will remain behind in terms of GDP per capita, they will be able to continue to develop at a higher rate than AEs. Related to this point, the difference between the AAGR in the ascending wave and the descending wave is expected to be moderate.

\section{REFERENCES}

1. S. Solomou, Economic Cycles: Long economic Cycles and Business Cycles since 1870 (Manchester Univ. Press, Manchester, 1998).

2. U.S. Bureau of Labor Statistics. Labor Productivity and Costs. https://www.bls.gov/lpc/tables.htm.

3. A Decade after the Global Recession. Lessons and Challenges for Emerging and Developing Economies (World Bank Group, Washington D.C., 2019).

4. L. E. Grinin, A. V. Korotaev, and R. S. Grinberg, "Some problems of the global and Russian economies and cyclical dynamics," in Long economic Waves, Modern Economy, and Prospects for Future Transformations in the 21st Century, Ed. by L. E. Grinin (Uchitel, Moscow, 2019) [in Russian].

5. World Trade Statistical Review 2020. https://www.wto.org/english/res_e/statis_e/wts2020_e/ wts20_toc_e.htm.

6. The Long economic View. How Will the Global Economic Order Change by 2050? (PwC, London, 2017). https://www.pwc.com/gx/en/world-2050/assets/pwcthe-world-in-2050-full-report-feb-2017.pdf.

7. World Development Indicators. https://databank.worldbank.org/source/world-development-indicators.

8. L. E. Grinin and A. L. Grinin, "Kondratieff waves and some forecasts for the 21st century," in Arrigiev Readings on the Topic: "The Global Chaos of the Modern World Order: Essence, Development, and Ways of Overcoming. Problems of the World Reorganization in the Conditions of the Triple Transition Period.” Proc. Int. Sci.Pract. Conf., May 16-18, 2019 (Orel, 2019), pp. 218-245.

9. Global Economic Prospects, June 2020 (World Bank, Washington, D.C., 2020).

10. World Economic Outlook Update June 2020 (International Monetary Fund, Washington D.C., 2020). https://www.imf.org/en/Publications/WEO/Issues/ 2020/06/24/WEOUpdateJune2020.

11. S. Yu. Glaz'ev, A. E. Aivazov, and V. A. Belikov, "Cyclical-wave theories of economic development and prospects for the world economy. Is the mid-term and long-term development of the world economy predictable?," Nauchn. Tr. Vol'nogo Ekon. O-va. Ross., No. 5, 177-211 (2019).

12. World Population Prospects 2019. https://population.un.org/wpp/DataQuery/.

Translated by A. Ovchinnikova 